\title{
Protein Tyrosine Phosphatases Expressed in the Developing Rat Brain
}

\author{
Mustafa Sahin and Susan Hockfield \\ Section of Neurobiology, Yale University School of Medicine, New Haven, Connecticut 06510
}

Previous studies of the developing nervous system have shown that cell-cell and cell-matrix interactions are involved in a variety of processes such as the proliferation, migration, and differentiation of neurons. While many cell-surface molecules have been identified, the signal transduction mechanisms through which they modify cellular responses are poorly understood. Recent studies have described a new and large family of enzymes, protein tyrosine phosphatases (PTPases), that may play a key role in transduction of cell surface events. Opposing the actions of protein tyrosine kinases (PTKs), PTPases can determine the state of tyrosine phosphorylation of a protein and regulate its function. Within the family of PTPases, two subgroups have been characterized: low-molecular-weight cytoplasmic (nonreceptor) PTPases and high-molecular-weight transmembrane (receptor) PTPases. Many receptor PTPases have fibronectin type III and/or Ig-like domains in their extracellular domains, suggesting that they have dual functions: cell adhesion and signal transduction. Such molecules may play a role in cellular recognition events that mediate the accurate assembly of the nervous system.

Using polymerase chain reaction with degenerate primers and a neonatal rat cortex cDNA library, we have identified a number of putative PTPase domains expressed in brain. Three are characterized here. These three sequences are most abundantly expressed in the developing cortex and so are named cortex-enriched protein tyrosine phosphatases (CPTPs) 1, 2, and 3. CPTP1 and CPTP3 show sequence homology to receptor PTPases and detect multiple high-molecular-weight mRNAs that are expressed preferentially in the developing CNS. Analysis of a longer cDNA indicates that CPTP1 and CPTP3 are the first and second phosphatase domains of a single receptor PTPase. CPTP2 identifies a single, smaller mRNA species with sequence homology to nonreceptor PTPases. Within the CNS, mRNAs detected by all three CPTPs are expressed at highest levels during prenatal and early postnatal days and are downregulated in the adult. In situ hybridization demonstrates that the CPTPs are expressed by progenitor cells and developing neurons. The

\footnotetext{
Received Apr. 6, 1993; accepted June 7, 1993.

We thank Suresh Karne for advice on PCR, James Dowling for assistance in DNA sequencing, and Joe Musco for help with photography. We also thank members of the Hockfield lab for critical reading of the manuscript. This work was supported by NIH Grant NS22807. M.S. is supported by a predoctoral fellowship from Merck Research Laboratories.

Correspondence should be addressed to Mustafa Sahin, Section of Neurobiology, Yale University School of Medicine, Sterling Hall of Medicine C-405, New Haven, CT 06510.

Copyright (C) 1993 Society for Neuroscience $0270-6474 / 93 / 134968-11 \$ 05.00 / 0$
}

spatial and temporal regulation of CPTPs suggests that they may play a role in neuronal development.

IKey words: tyrosine phosphatase, polymerase chain reaction, neocortex, rat, embryo, in situ hybridization, neurogenesis]

During the development of the mammalian CNS, a plate of morphologically undifferentiated progenitor cells undergoes a period of rapid cellular proliferation to give rise to all the cells, both neurons and glia, that will comprise the mature CNS. The cellular processes that mediate cellular proliferation, the migration of newly born neurons to their final locations, the elaboration of characteristic dendritic arbors, and the precision of axon route and target specificity are beginning to be explored. A number of different studies indicate that many of the events in the generation and differentiation of cells in the developing nervous system require a complex series of cell-cell interactions. For cxample, the fate of cortical or retinal neurons is determined at least in part by interactions that occur at the time of a neuron's final mitosis (Reh and Kljavin, 1989; McConnell and Kaznowski, 1991). While the precise mechanisms that might govern these kinds of interactions are not currently well understood, proteins that mediate cell-cell recognition and that transduce signals from the cell surface to intracellular locations are likely to have important roles in such events (Elkins et al., 1990; Hynes and Lander, 1992).

One of the most ubiquitous intracellular signaling systems is phosphorylation of proteins on serine, threonine, and tyrosine residues. Regulation of protein function through tyrosine phosphorylation is known to be critical in the control of many developmental processes, including cellular proliferation and differentiation. Growing evidence suggests that tyrosine phosphorylation and dephosphorylation may also play key roles in ncural development (Wagner et al., 1991). The opposing actions of protein tyrosine kinases (PTKs) and protein tyrosine phosphatases (PTPases) determine the state of protein tyrosine phosphorylation. A growing number of PTKs and PTPases have been identified in various species and tissues, including the mammalian CNS.

In the developing nervous system, studies of growth factor receptors and Drosophila mutants have significantly advanced our understanding of the functional significance of PTKs. The trk family of tyrosine kinases, first identified as genes with oncogenic potential, have now been shown to function as highaffinity neurotrophin receptors (Chao, 1992). In addition, the receptors for other peptide growth factors, such as platelet-derived growth factor, basic fibroblast growth factor, epidermal growth factor, and insulin-like growth factor, are also transmembrane tyrosine kinases that are expressed in neural tissues 
(Chao, 1992; Schlessinger and Ullrich, 1992). The function of receptor tyrosine kinases has also been studied extensively with genetic techniques in Drosophila (reviewed in Shilo, 1992). Drosophila PTK mutants demonstrate that these molecules are crucial for the determination of neuroblast identity in the CNS [faint little ball (Schejter and Shilo, 1989)], for establishing the number and spacing of photoreceptors in the eye imaginal disk [cllipse (Baker and Rubin, 1989)], for differentiation of the R7 photoreceptors [sevenless (Rubin, 1991)], and for glial migration [breathless (Klambt et al., 1992)]. Several novel putative PTKs are expressed preferentially in the embryonic and early postnatal rodent CNS (Lai and Lemke, 1991), consistent with a role in mammalian neural development.

While there is ample evidence that PTKs play an important role in neural development, much less is known about the PTPases. Tyrosine dephosphorylation has been associated with cellular differentiation in a number of non-neural tissues. For instance, during granulocytic differentiation of leukemia cell lines, phosphotyrosine residues decrease while PTPase activity increases (Frank and Sartorelli, 1988). Since phosphorylation is a reversible process, one might predict that PTPases, like PTKs, play important roles in the development of the nervous system. Indeed, an increase in PTPase activity is associated with NGFinduced neuronal differentiation of PC12 cells (Aparicio et al., 1992), and two recently identified Drosophila receptor PTPases are selectively expressed on subsets of developing axons (Tian et al., 1991; Yang et al., 1991). Perhaps of greatest interest in regard to possible roles in cell-cell signaling, many receptor PTPases (including those identified in the Drosophila nervous system) have fibronectin type III (FN-III) and/or immunoglobulin (Ig)-like domains in their cxtraccllular domains, suggesting that they may have dual functions: cell adhesion and signal transduction.

While few PTPases have been reported in the developing brain, the level of tyrosine phosphorylation indicates that PTPases must be particularly active early in neurogenesis (Maher, 1991). Furthermore, the increasingly large number of PTKs with demonstrated activity during neural development implies that there may also be a large group of PTPases involved in neuronal growth and differentiation. Given the possible function of PTPases in the determination of cellular phenotype and our interest in the generation of cellular diversity in the mammalian CNS (Hockfield and McKay, 1985; Geschwind and Hockfield, 1989; Hockfield and Sur, 1990; Martin et al., 1992), we have examined the expression of PTPases in the neonatal rat CNS. Using a polymerase chain reaction (PCR)-based approach, we have identified a number of DNA sequences that encode putative PTPase domains and present here the characterization of three of these. All three are enriched in the nervous system during embryonic and early postnatal days. The temporal and spatial regulation of expression of the mRNAs identified by these sequences suggests that they encode proteins that may participate in neuronal development.

\section{Materials and Methods}

RNA extraction and cDNA library synthesis. Total cellular RNA was extracted from cerebral neocortex of postnatal day 0 (P0) SpragueDawley rats using the guanidine thiocyanate/cesium chloride ultracentrifugation method (Bothwell et al., 1990). PolyA ${ }^{+}$RNA was isolated by one pass through an oligo-dT cellulose (type III, Collaborative Research) affinity column (Sambrook et al., 1989). Oligo-dT-primed cDNA synthesis was carried out with the Superscript Plasmid kit (GIBCO/ Bethesda Research Labs). Briefly, the kit uses a NotI primer-adapter and $\mathrm{RNaseH}^{-} \mathrm{M}-\mathrm{MLV}$ reverse transcriptase for the first-strand syn- thesis and Escherichia coli RNase H, DNA pol I, and DNA ligase for the second-strand synthesis. Double-stranded cDNA was blunt-ended with T4 DNA pol, cut with NotI, and size fractionated by column chromatography. cDNAs larger than 500 base pairs (bp) were ligated directionally into a modified Bluescript vector, E61, gift of J. L. R. Rubenstein (Rubenstein et al., 1991). The cDNA library contained 3.2 $\times 10^{6}$ clones with an average insert size of $900 \mathrm{bp}$. For the Northern analysis, the same methods were utilized to extract total RNA from cortex without hippocampus at embryonic day 16 (E16), P0, P4, P14, P30, and adult; P0 and P35 liver; P35 kidney; and P14 and adult spinal cord.

$P C R$ amplification. The cDNA library was used as a template for amplification using Taq polymerase (GeneAmp, Perkin Elmer) and degenerate primers (see Fig. 1 for position and sequence of primers). Twenty-five picomoles each of sense and antisense primers were used in $25 \mu \mathrm{l}$ reactions in Taq buffer $(10 \mathrm{~mm}$ Tris- $\mathrm{HCl} \mathrm{pH} 8.3,50 \mathrm{~mm} \mathrm{KCl}$, $1.5 \mathrm{mM} \mathrm{MgCl}_{2}, 0.001 \%$ gelatin) with 0.6 units of Taq polymerase, 200 $\mu \mathrm{M}$ dNTPs, and $25 \mathrm{ng}$ of cDNA library as template. PCR was carried out in a Perkin Elmer DNA Thermal Cycler for 35 cycles. Each cycle included a $30 \mathrm{sec}$ denaturation at $94^{\circ} \mathrm{C}$ and a $3 \mathrm{~min}$ extension at $72^{\circ} \mathrm{C}$. In order to facilitate the anncaling of the degencratc primers, the initial five cycles included a $1 \mathrm{~min}$ annealing step at $37^{\circ} \mathrm{C}$ and a slow ramp $\left(1^{\circ} \mathrm{C}\right.$ per $\left.4 \mathrm{sec}\right)$ between annealing and extension. The subsequent 30 cycles utilized $1 \mathrm{~min}$ annealing step at $45^{\circ} \mathrm{C}$ with no ramp. One microliter aliquots of the reaction were used to ligate the amplified fragments into the TA vector (Invitrogen). Plasmids with inserts were chosen by blue/ white selection and examined by PCR with the original degenerate primers for the presence of PTPase domains. Inserts that gave a band of the appropriate size ( $350 \mathrm{bp}$ ) after PCR were sequenced by the dideoxy-chain termination method (Sequenase, U.S. Biochemical) on both strands using M13 (-40) forward and reverse primers. Sequence analyses were conducted using GCG software (Genetics Computer Group 1991).

Northern hybridization. Northern analyses were performed using standard methods (Bothwell et al., 1990). Total $(25 \mu \mathrm{g})$ or polyA ${ }^{+}(1-2 \mu \mathrm{g})$ RNA was denatured in $2.2 \mathrm{M}$ formaldehyde, $50 \%$ formamide, $1 \times$ MOPS buffer at $65^{\circ} \mathrm{C}$ for $15 \mathrm{~min}$. RNA was resolved by electrophoresis on a $1.0 \%$ agarose gel containing $2.2 \mathrm{~m}$ formaldehyde and $1 \times$ MOPS buffer transferred to Zeta-probe (Bio-Rad) by capillary blotting, and then baked $\left(80^{\circ} \mathrm{C}\right)$ under vacuum for $2 \mathrm{hr}$. Hybridization was carried out in $7 \%$ SDS, $1 \%$ BSA, 0.5 м phosphate buffer $\mathrm{pH} 6.8(\mathrm{~PB}), 1 \mathrm{~mm}$ ED'TA for at least $8 \mathrm{hr}$ at $65^{\circ} \mathrm{C}$ (Church and Gilbert, 1984). Hybridization solution contained $1-3 \times 10^{6} \mathrm{cpm} / \mathrm{ml}$ of probe made by random primed labeling of the PCR fragments for each PTPase clone (Boehringer Mannheim). For random priming, PCR fragments were either gel purified using GeneClean (American Bioanalytical) or isolated using Magic PCR Preps (Promega). After labeling with ${ }^{32} \mathrm{P}$-dCTP (Amersham), the specific activity of the probes was $2-8 \times 10^{8} \mathrm{cpm} / \mu \mathrm{g}$. After hybridization, filters wcre washed twice in 5\% SDS, $0.5 \%$ BS $\Lambda, 40 \mathrm{~mm}$ PB, $1 \mathrm{~mm}$ EDTA and four times in $1 \% \mathrm{SDS}, 40 \mathrm{~mm} \mathrm{~PB}, 1 \mathrm{~mm}$ EDTA at $65^{\circ} \mathrm{C}$ for $20 \mathrm{~min}$. Cyclophilin, which is present at a constant relative abundance throughout development (Lenoir et al., 1986), was used as a control for equal loading of lanes. RNA molecular weight standards (GIBCO/Bethesda Research Labs) were included on the blots to estimate the sizes of the transcripts. Densitometry of the autoradiograms was performed on the LKB Ultrascan XL system.

In situ hybridization. In situ hybridization was performed as in Martin et al. (1992). Twelve-micron-thick frozen sections were thaw mounted onto gelatin-coated slides, postfixed, and dehydrated. Sections were prehybridized in $2 \times$ saline-sodium citrate (SSC) $50 \%$ formamide at $50^{\circ} \mathrm{C}$. for $1 \mathrm{hr}$. Tissues were then hybridized in $50 \%$ formamide, $1 \times$ Denhardt's, $0.75 \mathrm{M} \mathrm{NaCl}, 10 \%$ dextran sulfate, $15 \mathrm{mM}$ dithiothreitol, 10 mM Tris-HCl pH 7.5, $1 \mathrm{~mm}$ EDTA, $0.5 \mathrm{mg} / \mathrm{ml}$ tRNA, $100 \mu \mathrm{g} / \mathrm{ml}$ salmon sperm DNA, and $1-2 \times 10^{6} \mathrm{cpm}$ probe at $50^{\circ} \mathrm{C}$ for $8-12 \mathrm{hr}$. The ${ }^{35} \mathrm{~S}$ CTP (New England Nuclear) labeled probes were generated using the T7 and SP6 promotors in the TA vector and the Riboprobe system (Promega). Neurofilament-middle (NF-M) antisense and CPTP3 sense probes were used as positive and negative controls, respectively (Martin et al., 1992). The negative control did not give a signal. Following hybridization, the slides were treated with $20 \mu \mathrm{g} / \mathrm{ml}$ RNase $A$ at $37^{\circ} \mathrm{C}$ for $30 \mathrm{~min}$. Final washes were done in $0.1 \times \mathrm{SSC}, 0.1 \% \beta$-mercaptoethanol at $65^{\circ} \mathrm{C}$ for $30 \mathrm{~min}$. Slides were then exposed to Kodak XAR film for $24-120 \mathrm{hr}$. Autoradiograms were used as negatives to print figures. To analyze the signal at higher resolution, the slides were dipped into emulsion, developed after 30-90 d, and counterstained with cresyl violet. 
Figure 1. PCR primers were constructed from the most conserved regions in the catalytic domain. $A$, Three members of the transmembrane PTPase family are shown to illustrate the extent of similarity in their first phosphatase domains: human CD45 (Streuli et al., 1987), human LAR (Streuli et al., 1988), and mouse LRP (Matthews et al., 1990). The alignments were produced using the BESTFIT function of the GCG program (Genetics Computer Group, 1991). Amino acids conserved among the three PTPases are indicated in boldface. Regions selected for primers are shown in boxes. $B$, Amino acid sequence used to generate the PCR primers. $C$, Degenerate nucleic acid sequence of the primers.

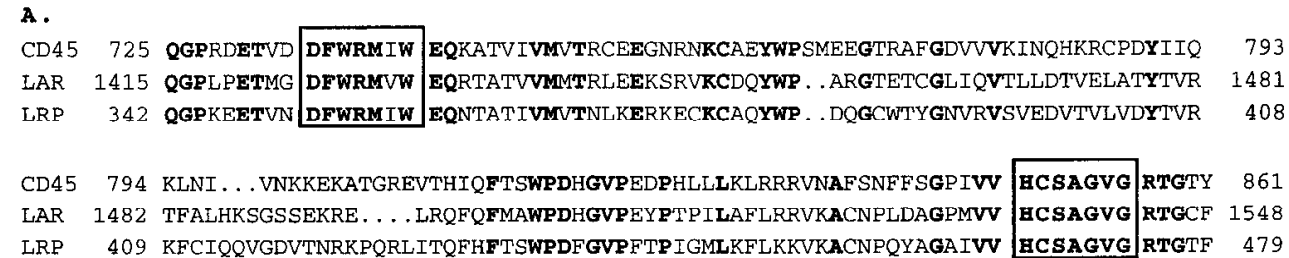

B.

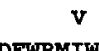

c $5 \cdot$ gactictgagaAtgatatge
CG GC
HCSAGVG

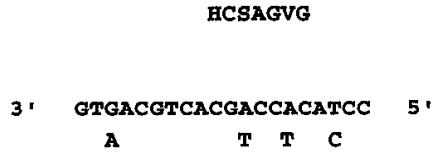

\section{Results}

PCR fragments encoding putative PTPase domains were isolated from a rat cortex $C D N A$ library

To identify PTPases expressed in neonatal rat cortex, PCR amplification was carried out with primers corresponding to the conserved catalytic domains of previously reported receptor PTPases. Oligonucleotide primers corresponding to amino acid sequences DFWRM(I/V)W (upstream) and HCSAGVG (downstream) were synthesized using most common codon usage tables to reduce degeneracy (Lathe, 1985) (Fig. 1). A P0 rat neocortex cDNA library was used as the DNA template for the amplification. To identify a wide range of receptor PTPases, PCR was performed with low-stringency annealing conditions (sce Materials and Methods). The PCR products were ligated directly into the TA vector without size selection. Of 51 isolates carrying inserts, 11 showed significant homology to the catalytic domain of previously reported PTPases.

The 11 sequences fall into five groups (Fig. 2). The first group contains six clones with identical sequences, all of which are highly homologous (97\%) in nucleotide sequence and $99 \%$ identical in amino acid sequence to phosphatase domain I of mouse leukocyte common antigen (LCA)-related phosphatase (LRP) (Matthews et al., 1990). The second group is made up of two clones with sequences identical to phosphatase domain $\mathrm{I}$ of rat LCA-related molecule, LAR (Pot et al., 1991). Both LRP and LAR are ubiquitously expressed and have been detected in the brain in previous studies (Saito and Streuli, 1991). The remaining clones (groups 3-5) contain sequences that are not identical to any PTPases in the databases. They also lack significant identity to one another. We refer to these clones as cortexenriched protein tyrosine phosphatases (CPTPs) 1, 2, and 3.

The deduced amino acid sequences of CPTP1 and CPTP3 show high homology to human receptor PTPase LAR (Streuli et al., 1988) and HPTP $\delta$ (Krueger et al., 1990). CPTP1 encodes an amino acid sequence with $85 \%$ and $88 \%$ identity to the first phosphatase domains of human LAR and HPTP $\delta$, respectively. Nucleotide sequence identity is approximately $75 \%$ with many conservative base substitutions. CPTP3, on the other hand, is almost identical to the second catalytic domains of LAR and $\operatorname{HPTP} \delta(94 \%$ and $97 \%$ amino acid identity, respectively). Nucleotide sequence identity in this region is about $85 \%$. The homology of CPTP1 and CPTP3 to rat LAR is slightly less than the homology to human LAR and HPTP $\delta$. These data indicate that CPTP1 and CPTP3 belong to the LAR subfamily of receptor PTPases, but neither is identical to rat $L \Lambda R$.

The sequence of CPTP2 (Fig. 2) includes regions that encode the consensus amino acids within the PTPase domains. The

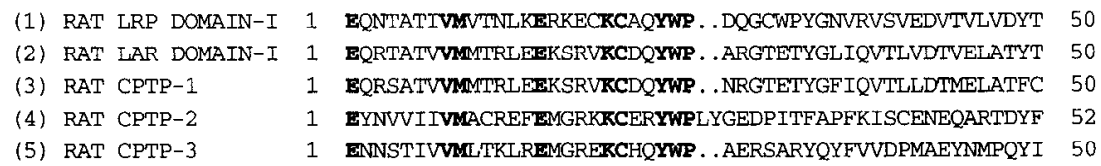

(1) RAT LRP D-I 51 VRKFCIQQVGDVTINRKPQRLITQFHFTSWPDFGVPFTPIGMLKFLKKVKACNPQYA. .GAIVV 111

(2) RAT LAR D-I 51 MRTFALHKSGSSEKRE. . . . LRQFOFMAWPDHGVPEYPTPILAFLRRVKACNPLDA. .GPMVV 107

(3) RAT CPTP-1 51 VRTESL.HKNGSSEKRE. . . VRHFQFTAWPDHGVPEYPTPFLAFLRRVKTCNPPDA. .GPVVV 106

(4) RAT CPTP-2 53 IRTLLL. .EFONESRR. . . . LYQFHYVNWPDHDVRSSFDSILDMISLMRKYQEH. .EDVPICI 107

(5) RAT CPTP-3 51 LREFKVTDARDGQSRT. . . VRQFQFTDWPEQGAPKSGEGFIDFIGQVHKTKEQFGQDGPISV 106

Figure 2. Deduced amino acid sequences of the PCR-amplified cDNAs from the P0 rat neocortex library. PCR from the P0 cortex library resulted in the identification of five groups of putative PTPase domains. Groups 1 and 2 correspond to phosphatase domain I of rat LRP and LAR, respectively. Novel sequences (groups 3-5) are called rat cortex-enriched protein tyrosine phosphatases (CPTPs). Amino acid sequences deduced from the nucleotide sequence of the PCR subclones flanked by the primers were aligned using the PILEUP function of the GCG program (Genetics Computer Group, 1991). Amino acids encoded by the PCR primers are not shown. Amino acids shown in boldface are conserved among the five clones as well as among other PTPases. 


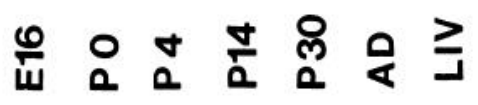

A

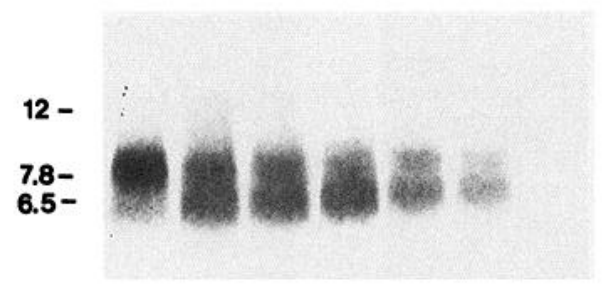

B

3.5-

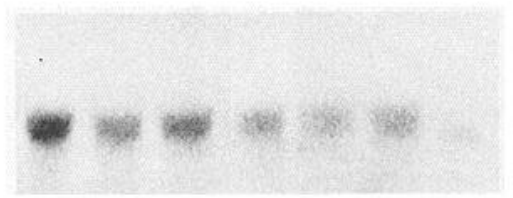

C

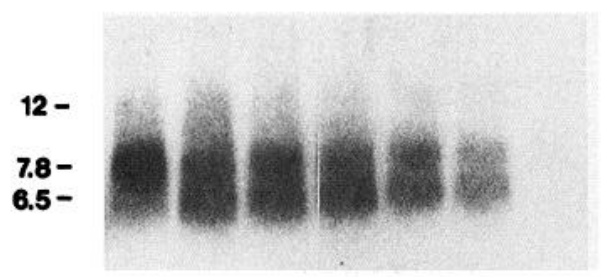

D

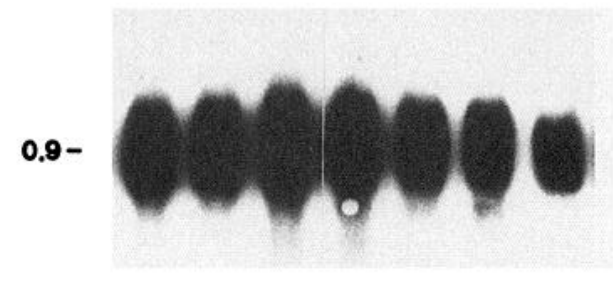

E

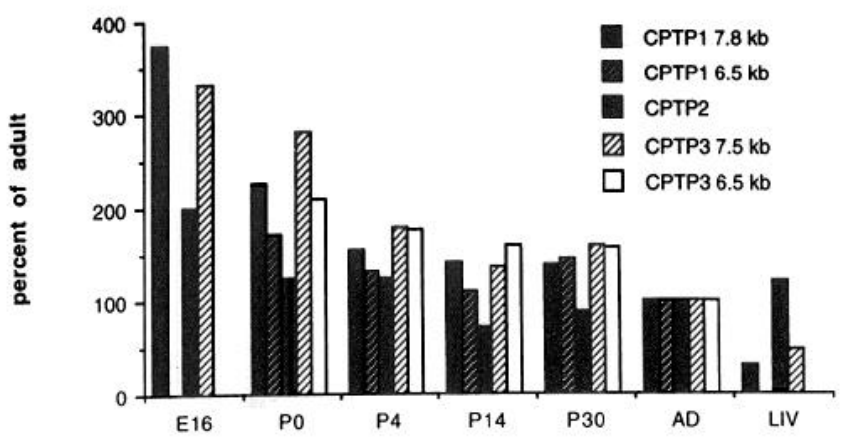

Figure 3. CPTP mRNA expression during development. $A-D$, Total RNA extracted from cortex on E16 and P0, P4, P14, P30, and adult $(A D)$ as well as $\mathrm{P} 35$ liver $(L I V)$ were run in formaldehyde-agarose gels, blotted onto nitrocellulose. The same blot was used for four rounds of hybridization separately with ${ }^{32} \mathrm{P}$-labeled cDNA probes for CPTP1 $(A)$, CPTP2 $(B)$, CPTP $3(C)$, and control probe cyclophilin $(D)$. The size of the transcripts was calculated using RNA molecular weight markers and is indicated at the left of each blot. E. Following exposure to the film, densitometry of the autoradiograms was performed for each transcript. To determine the relative abundance of each transcript in the RNA samples, the ratio of absorbance of each CPTP band to that of the cyclophilin band was calculated. In the graph, these values are presented as a percentage of the value in the adult cortex. According to this analysis, highest level of expression for CPTP2 and the $7.8 \mathrm{~kb}$ bands of CPTP1 and CPTP3 are found at E16. The $6.5 \mathrm{~kb}$ bands of CPTP1 and closest similarity (64\% amino acid identity) is to a cytoplasmic PTPase, PEP(PEST-domain phosphatase), isolated from a mouse hematopoietic cell line (Matthews et al., 1992).

\section{CPTPS recognize developmentally regulated $m R N A s$ in the rat neocortex}

The size, tissue distribution, and developmental expression of RNA species encoding the CPTPs were determined by Northern blot analysis using the identified phosphatase domains. RNA samples isolated from rat neocortex at different embryonic and postnatal ages, as well as postnatal spinal cord, liver, and kidney, were probed with radiolabeled PCR fragments for each CPTP. Confirmation of equal loading of the lanes was obtained by reprobing the blots for cyclophilin. Densitometry was used to determine the temporal regulation of the CPTP transcripts in the brain, where the ratio of absorbance of individual CPTP bands to that of the cyclophilin band was calculated for each RNA sample. Cyclophilin was used as a control because it is present at a constant relative abundance throughout brain development (Lenoir et al., 1986), in contrast to actin or tubulin, whose relative abundance in the brain varies with age (Schmitt et al., 1977; Geschwind and Hockfield, 1989). Cyclophilin is not, however, expressed at equivalent levels in different organs. For instance, it is expressed at lower levels in the liver than in the brain (Danielson et al., 1988).

For CPTP1, two prominent transcripts are detected in the rat cortex, 6.5 kilobases $(\mathrm{kb})$ and $7.8 \mathrm{~kb}$ (Fig. $3 A$ ). The $7.8 \mathrm{~kb}$ message is preferentially expressed in the CNS, but is also weakly expressed in the liver and kidney. In the cortex, this message is the predominant transcript during the embryonic period and is found at high levels at E16. The expression of the $7.8 \mathrm{~kb}$ transcript falls by $\mathrm{P} 4$ and is relatively constant thereafter (Fig. $3 E$ ). In contrast, the $6.5 \mathrm{~kb}$ message is not detected in the E16 cortex. Its expression begins around birth, quickly approaches that of the $7.8 \mathrm{~kb}$ species during early postnatal days, and remains relatively constant throughout the remainder of the animal's life (Fig. $3 E$ ). The $6.5 \mathrm{~kb}$ band appears to be neural tissue specific; it is not detected in RNA samples from adult liver (Fig. 3A). This species is similarly absent in RNA from adult kidney and P0 liver (data not shown). A high-molecular-weight transcript $(12 \mathrm{~kb})$ is also detectable at longer exposures. All three transcripts for CPTP1 are detected in postnatal spinal cord at levels similar to those found in postnatal cortex (not shown).

For CPTP2, a single mRNA species of $3.5 \mathrm{~kb}$ is observed (Fig. $3 B$ ). In the cortex, this transcript is detectable at high levels at E16. The level of cortical expression declines around birth and remains close to adult levels after P4 (Fig. $3 E$ ). The level of expression of CPTP2 in adult cortex is similar to that in the adult liver (Fig. 3B), spinal cord, and kidney (not shown).

RNA detected with CPTP3 parallels CPTP1 in size, tissue distribution, and developmental regulation (Fig. $3 C, E$ ). The CPTP3 probe hybridizes to two prominent bands at 6.5 and 7.8 $\mathrm{kb}$. While the $7.8 \mathrm{~kb}$ band is more abundant in prenatal cortex, both bands are expressed at equal levels postnatally. The 6.5 $\mathrm{kb}$ form is not found in the liver. A higher-molecular-weight $(12 \mathrm{~kb})$ transcript is faintly detected in neural tissues. As discussed in more detail below, the correspondence between the

CPTP3 are detected at approximately equal levels in RNA samples from cortex at all postnatal ages, but are not detected in RNA samples from the E16 cortex or P35 liver. 

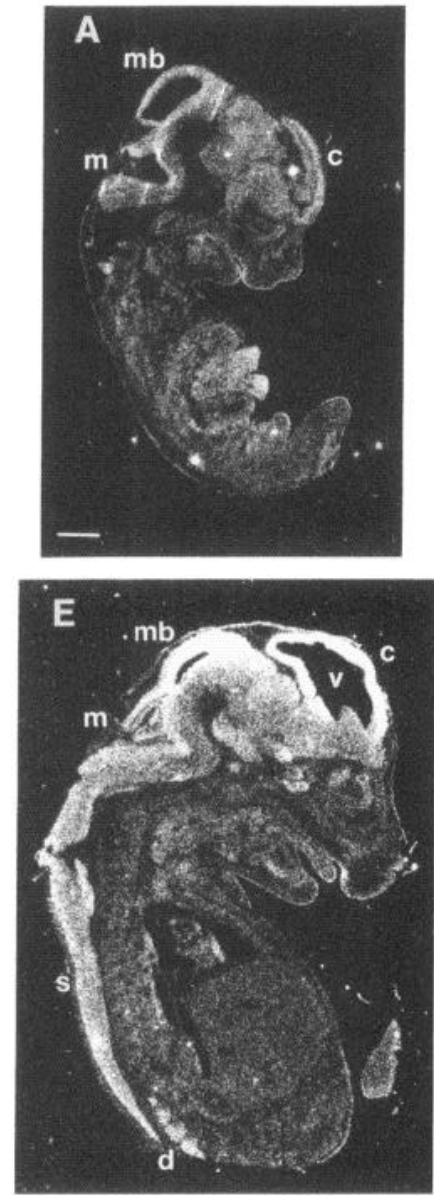
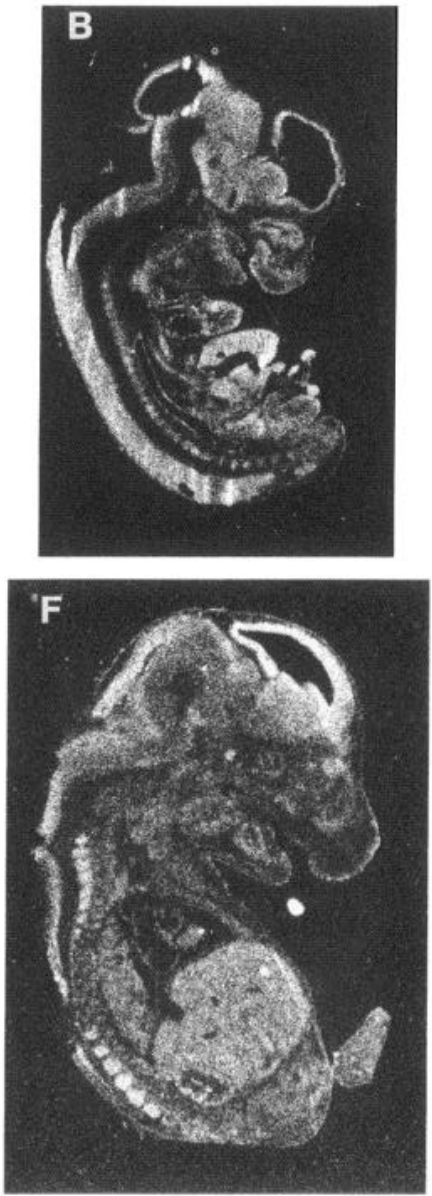
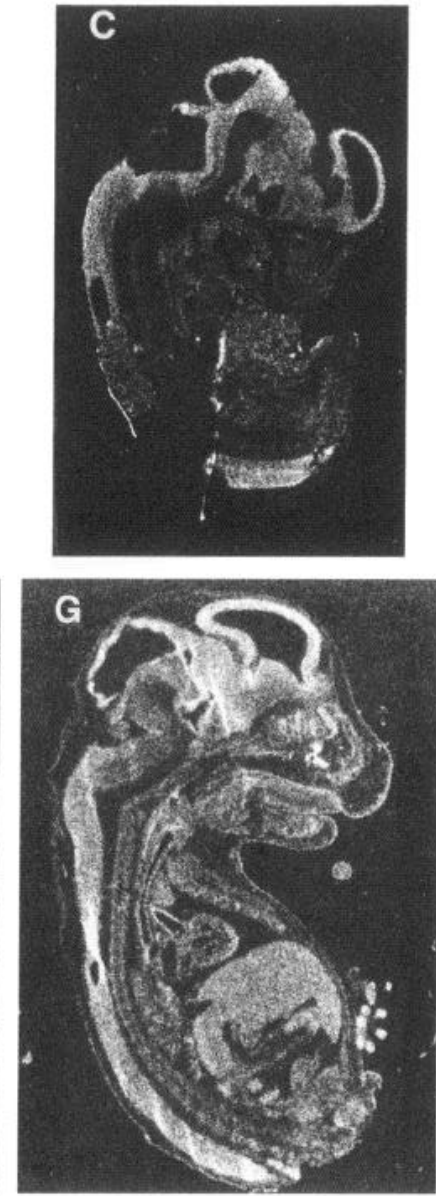
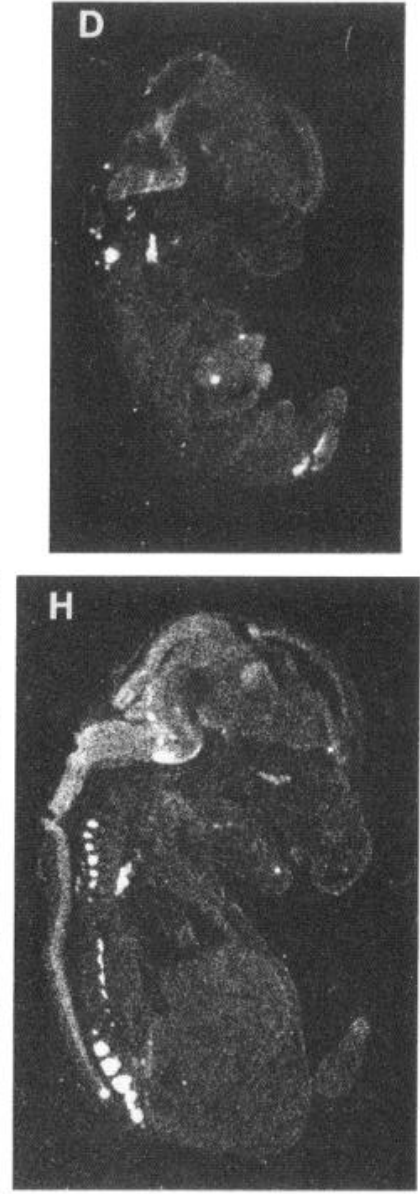

Figure 4. In situ hybridization demonstrates that CPTPs are expressed in the CNS during embryonic development. Parasagittal sections from E15 $(A-D)$ and E17 $(E-H)$ animals were hybridized to ${ }^{35}$ S-labeled antisense RNA probes for CPTP1 $(A, E)$, CPTP2 $(B, F)$, CPTP3 $(C, G)$, and NF-M $(D, H)$ as control probe. $A$, At E15, a high CPTP1 signal is detected in the cerebral cortex $(c)$, midbrain $(m b)$, and medulla $(m)$. $B$, CPTP2 mRNA is present throughout the CNS including the spinal cord. $C$, CPTP3 mRNA is expressed at high levels in the cerebral cortex and the midbrain. There is less but significant labeling in the medulla and the spinal cord. D, NF-M signal is detected at the sacral end of the spinal cord, but only weakly in the medulla and at even lower levels in the telencephalon. $E$, At E17, CPTP1 mRNA is found at highest levels within the cortex $(c)$ surrounding the lateral ventricle $(v)$ and in the midbrain $(m b)$. Lower signal is detected in the medulla $(m)$, spinal cord $(s)$, and the DRG $(d)$. $F$, In a near-adjacent section, CPTP2 message is detected throughout the CNS and in the DRG, with highest expression in the cortex. $G$, At E17, CPTP3 signal is seen at high levels in the cortex and at somewhat lower levels in more caudal regions of the CNS. $H$, NF-M signal is expressed at higher levels in the DRG than the CNS; a weak signal is detectable in the spinal cord and medulla and an even weaker signal in the cortex. Scale bar, $1 \mathrm{~mm}$.

transcripts detected by CPTP1 and CPTP3 suggests that they may represent the two phosphatase domains of a single PTPase gene.

\section{CPTPs are expressed in the CNS during embryonic and postnatal development}

To determine the spatial distribution of CPTP mRNAs during development, we performed in situ hybridization using radiolabeled antisense RNA. Both embryonic and postnatal CNS tissues were analyzed by this method. Near adjacent sections were probed with NF-M as a positive control for neuronal RNA expression.

CPTP1. During embryogenesis, CPTPl expression is higher in the nervous system than in non-neural tissues. CPTP1 mRNA is detected in E15 embryos at high levels in the CNS (Fig. 4A). At this stage, CPTP1 mRNA is widely distributed in the CNS including the cortex, midbrain, medulla, and spinal cord and peripherally in the dorsal root ganglia (DRG). At E15, many parts of the CNS do not exhibit a strong hybridization signal to
NF-M probe (Fig. 4D). Thus, CPTP1 appears to be expressed before neurons start expressing neurofilament. By E17, CNS expression of CPTP1 has increased, with highest transcript levels detected in the developing dorsal telencephalon and midbrain (Fig. $4 E$ ). Around the lateral ventricles, the level of CPTP1 expression is higher in the developing cortex than in the ganglionic eminence. More caudal regions of the nervous system such as the spinal cord and DRG express CPTP1, but at somewhat lower levels than in the cortex and midbrain.

During postnatal development, CPTP1 transcripts are detected nonuniformly in the brain. At P4, the highest levels of CPTP1 are found in the neocortex, hippocampus, and cerebellum (Fig. 5A). Within the neocortex, CPTP1 mRNA appears most abundant in the superficial layers and the subplate (Figs. $5 A, 6 B$ ). This hybridization pattern is markedly different from the pattern of NF-M expression, where hybridization is most intense in the middle layers of the neocortex (Fig. 5D), correlating with a higher neuronal density. CPTP1 and NF-M also show different patterns of expression in the developing cere- 

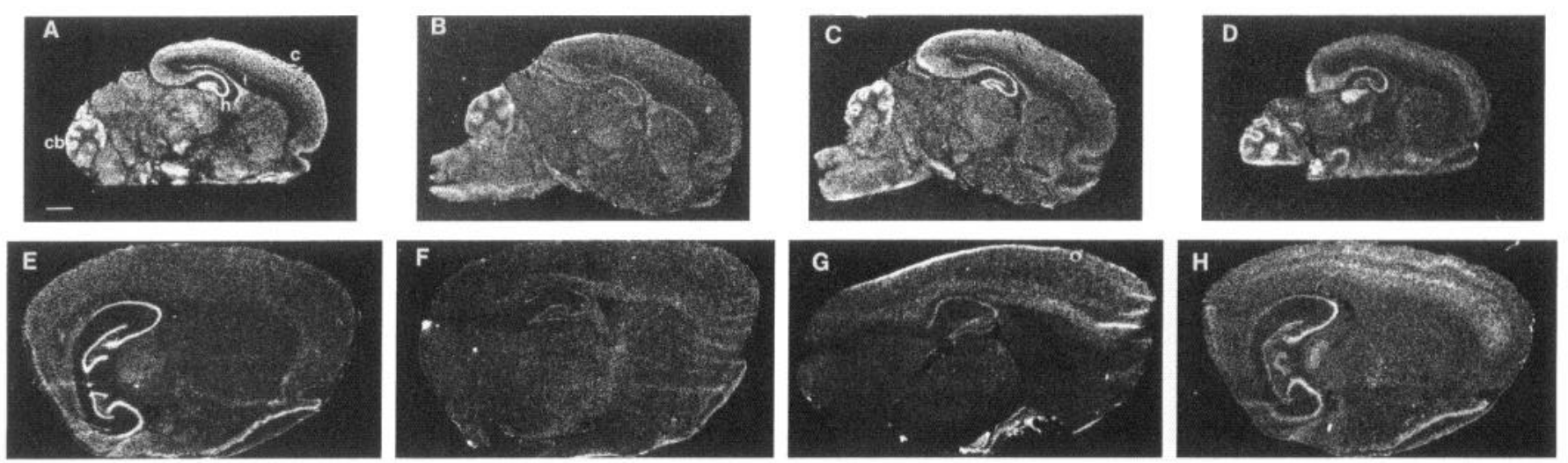

Figure 5. CPTP expression in postnatal brain. Parasagittal sections from P4 $(A-D)$ and adult $(E-H)$ brains were hybridized to ${ }^{35}$ S-labeled antisense RNA probes for CPTP1 $(A, E)$, CPTP2 $(B, F)$, CPTP3 $(C, G)$, and NF-M $(D, H)$ as control. $A$, At P4, a high level of CPTP1 signal is detected in the neocortex $(c)$, cerebellum $(c b)$, and hippocampus $(h)$. Within the neocortex, signal is especially high in the superficial layers and the subplate (arrow). In the cerebellar cortex, two bands of CPTP1 signal are detected, in the external and internal granular layers (see also Fig. 6D). In the hippocampus $(h)$, all CA fields and the dentate gyrus exhibit high levels of CPTP1 hybridization. $B$, CPTP2 signal is seen most prominently in the cerebellum, while the rest of the brain displays diffuse hybridization. $C$, CPTP3 mRNA is detected in a pattern very similar to CPTP1 (in $A$ ). Signal is most intense in the neocortex, hippocampus, dentate gyrus, and cerebellar cortex. $D$, NF-M is abundant in neocortex, hippocampus, thalamus, and cerebellum. Within the neocortex, the highest signal is in the middle layers. In the cerebellum, the most superficial layer (external granular layer) shows less signal than the deeper layers. $E$. In adults, the highest levels of CPTP1 mRNA is detected in the CA fields of hippocampus, dentate gyrus, and entorhinal cortex. The neocortex displays only a diffuse signal. $F$, CPTP2 message is detected at very low levels throughout the brain. $G$, CPTP3 mRNA is expressed diffusely in the neocortex and hippocampal formation. $H$, NF-M message in the adult is most prominent in the hippocampus and neocortex, but is detectable throughout the brain. Scale bar, $1 \mathrm{~mm}$.

bellum. At P4, CPTP1 is expressed in both the external and internal granular layers (Figs. $5 A, 6 D$ ) while NF-M appears to be excluded from the external granular layer (Fig. 5D). CPTP1 expression in the adult neocortex is lower than at $\mathrm{P} 4$ while adult hippocampus and entorhinal cortex continue to express this message at significant levels (Fig. $5 E$ ).

The expression of CPTP1 in the spinal cord follows a developmental regulation similar to that in the forebrain. CPTP1 is expressed throughout the rostrocaudal extent of the spinal cord at embryonic ages (Fig. 4E). At P4, CPTP1 is expressed in the spinal gray matter, with somewhat higher levels of expression in the dorsal horn (Fig. 7A). NF-M is expressed at higher levels in the ventral than in the dorsal horn (Fig. 7D). At higher magnification, CPTP1 signal is seen associated with neurons (Fig. $6 F$ ). In the adult spinal cord, CPTP1 expression is diminished relative to early postnatal levels, but remains higher in gray matter than in white matter (Fig. $7 E$ ).

CPTP2. CPTP2 mRNA is widely distributed in the embryo, but the highest in situ signals are found in the CNS, DRG, and liver. Within the CNS at E15 and E17, the telencephalon exhibits the strongest hybridization (Fig. $4 B, F$ ). Postnatally, neocortical CPTP2 expression is markedly downregulated. At P4, the CPTP2 message is still expressed in the cerebellar cortex, but there is only a weak and diffuse signal present in the neocortical gray matter (Fig. 5B). This low level of expression persists in the adult brain (Fig. $5 F$ ). Within the spinal cord, CPTP2 is found at high levels in the gray matter during early postnatal periods. Hybridization is seen in both ventral and dorsal horns at P4 (Fig. $7 B$ ). In the adult spinal cord, the signal is less intense although still restricted to the gray matter (Fig. $7 F$ ).

CPTP3. The hybridization pattern of CPTP 3 in the CNS generally follows the pattern of CPTP1. In the embryonic CNS, CPTP3 mRNA is detected at highest levels in the cortex and midbrain at both E15 and E17 (Fig. 4C,G). Neocortical expression of CPTP3 persists into the early postnatal period. At $\mathrm{P} 4$, the hippocampus and cerebellum also show strong hybrid- ization to CPTP3. The CPTP3 expression in the cerebellum appears to be highest in the external and internal granular layers, similar to that seen with CPTP1 (Fig. $5 C$ ). In the adult, a diffuse signal is seen in the neocortex and hippocampus (Fig. 5G). In the spinal cord, CPTP3 is found throughout the gray matter at P4 (Fig. 7C). The distribution of the signal remains the same, but the intensity declines in the adult spinal cord (Fig. $7 G$ ).

\section{CPTP1 and CPTP3 represent the two phosphatase domains of a single PTPase gene}

Virtually all transmembrane PTPases have two conserved intracellular phosphatase domains. The similarity between the first phosphatase domains of different PTPases is higher than that between first and second domains within any single phosphatase. The same is true for the second phosphatase domains. Interestingly, CPTP1 is highly homologous to the first, and CPTP3 to the second, catalytic domains of LAR and HPTP $\delta$. Moreover, CPTP1 and CPTP3 have almost identical developmental expression profiles on northern blots and very similar patterns of expression by in situ hybridization. These observations suggest that CPTP1 and CPTP3 may represent the first and second catalytic domains of a new receptor PTPase. In order to verify this possibility, PCR was used to screen for cDNAs that contain both CPTP1 and CPTP3. A nondegenerate oligonucleotide primer internal to CPTP1 (corresponding to amino acids LATFCVR) and the degenerate downstream PTPase primer (see Fig. $1 C$ ) were used to amplify cDNAs from the P0 library. This amplification resulted in two PCR products with approximate molecular weights of 100 and 1100 bp (data not shown). Subcloning and sequencing of the large PCR product revealed that it contained CPTP1 sequences on the $5^{\prime}$ end and CPTP3 sequences on the $3^{\prime}$ end. The region in between CPTP1 and CPTP3 also showed high homology to rat and human LAR and to HPTP $\delta(82 \%, 84 \%$, and $88 \%$ amino acid identity, respectively). For simplicity, in the remainder of this article, we consider CPTP1 and CPTP3 together and refer to them as CPTP1. 
less label is detected in the underlying white matter $(w m)$. $C$ and $D$, CPTP1 mRNA is detected at high level in the external (single arrow) and internal (double arrow) granular layers of the cerebellum at P4. Between the two granular layers, the Purkinje cell layer is relatively devoid of hybridization. $E$ and $F$, In the ventral horn of P4 spinal cord, CPTP1 signal is very high over neurons in the gray matter (arrows). Note that hybridization in the neighboring white matter $(w m)$ is much less intense. Scale bars: $200 \mu \mathrm{m}$ for $A-D$, $100 \mu \mathrm{m}$ for $E$ and $F$
A

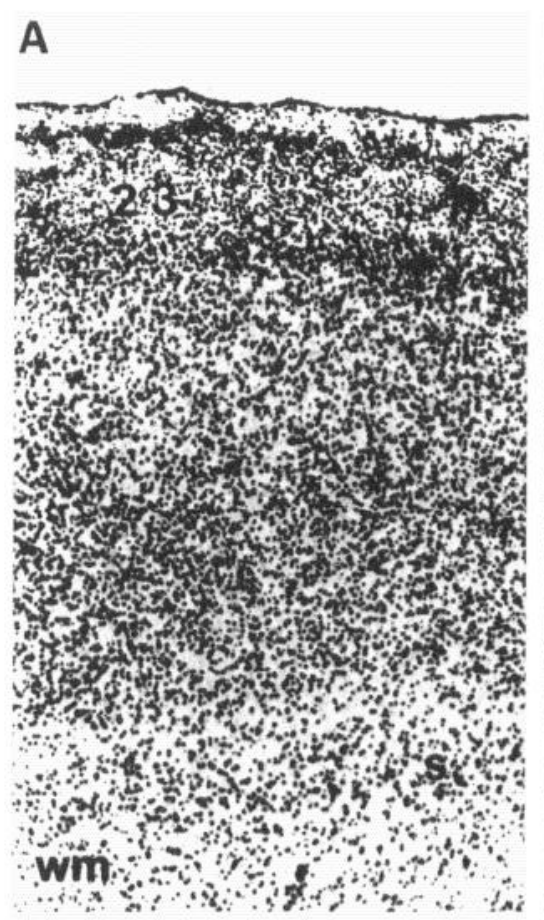

C
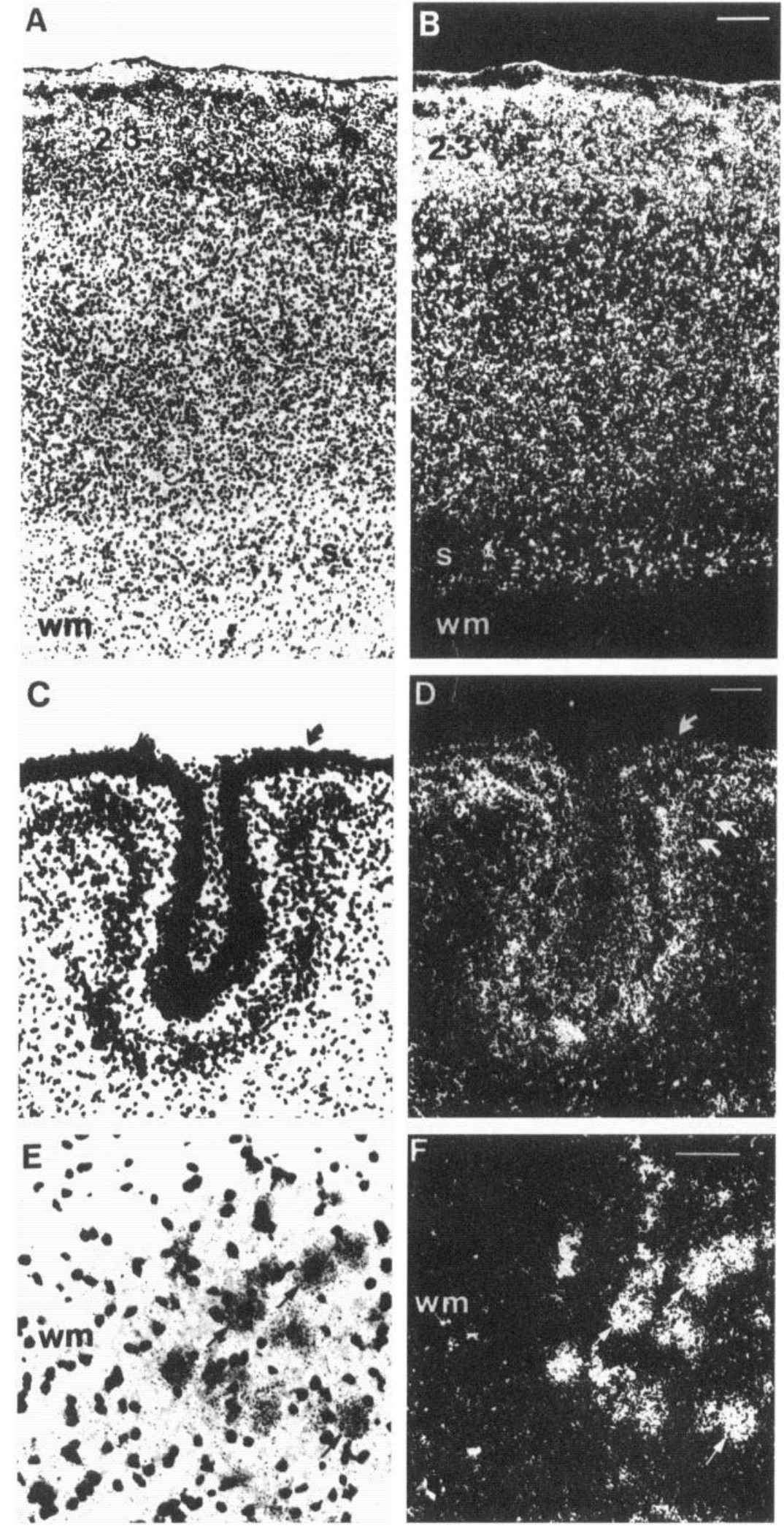

\section{Discussion}

We have identified five sequences encoding putative PTPase domains that are expressed in the developing rat neocortex. By in situ hybridization we demonstrate that three of these se- quences, CPTP1, CPTP2, and CPTP3, are expressed in the CNS by progenitor cells and by developing neurons. Although we have information for only a relatively small stretch of the cDNAs, each contains the consensus sequences found in the catalytic domains of previously characterized PTPases, strongly sug- 

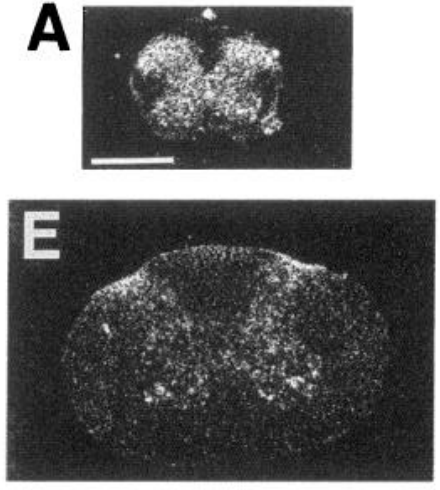
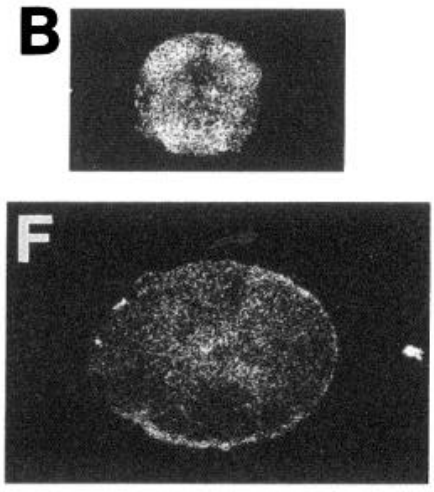
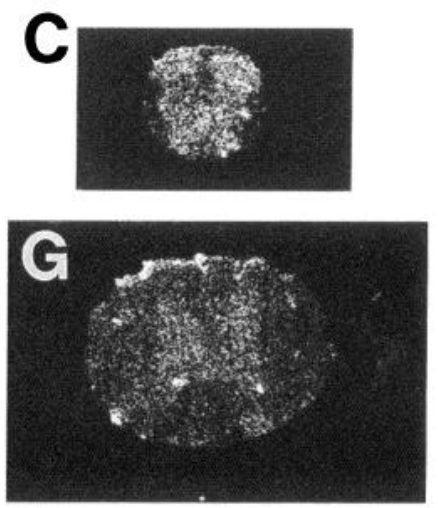
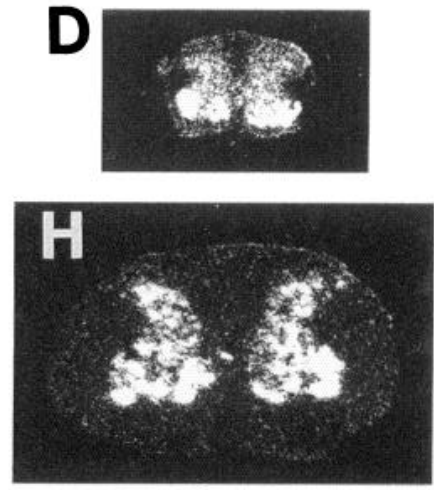

Figure 7. CPTP expression is restricted to gray matter in the spinal cord. Transverse sections from P4 $(A-D)$ and adult $(E-H)$ spinal cord were hybridized to ${ }^{35}$ S-labeled antisense RNA probes for CPTP1 $(A, E)$, CPTP2 $(B, F)$, CPTP3 $(C, G)$, and NF-M $(D, H)$ as control probe. At both ages, the sections for CPTP1 and NF-M are taken from cervical segments while those for CPTP2 and CPTP3 are from thoracic segments. $A$, CPTP1 is expressed throughout the spinal gray matter, with somewhat higher levels of expression in the spinal dorsal horn. $B-D$, Expression of CPTP2 $(B)$, CPTP3 $(C)$, and NF-M $(D)$ is similarly restricted to the gray matter. NF-M $(D)$ is expressed at higher levels in the ventral horn. $E-G$, In the adult, CPTP-1 $(E)$, CPTP2 $(F)$, and CPTP3 $(G)$ expression is diminished, but still greater in gray than in white matter. $H$, At this stage, NF-M is highly expressed throughout the spinal gray matter. Scale bar, $1 \mathrm{~mm}$.

gesting that they encode phosphatases. Analysis of a longer cDNA clone indicates that CPTP1 and CPTP3 represent the two phosphatase domains of a single PTPase gene.

In our PCR screen, each of the three CPTP sequences was obtained only once. Therefore, we cannot exclude the possibility that the nucleotide sequences of these clones contain rare incorporation errors due to the infidelity of Taq polymerase. However, when multiple copies of previously identified sequences were obtained (six clones of LRP and two of LAR), the sequences we obtained were identical to one another. Furthermore, in the case of rat LAR, the sequence of our PCR product was identical to the cDNA sequence in the GenBank. Therefore, if PCR errors occurred, they were probably infrequent. It is unlikely that incorporation errors could account for the three new putative phosphatase domains reported here.

\section{CPTPI may encode a novel receptor PTPase}

Recent PCR and low-stringency hybridization studies have led to the identification of many novel PTPases (reviewed in Fischer et al., 1991; Saito and Streuli, 1991; Charbonneau and Tonks, 1992; Pot and Dixon, 1992). Within the family of PTPases, two subfamilies have been described: low-molecular-weight cytoplasmic (nonreceptor) PTPases and high-molecular-weight transmembrane (receptor) PTPases. With the exception of two (HPTP $\beta$ and DPTP10D), all transmembrane phosphatases have two conserved intracellular phosphatase domains. The catalytic activity is associated with the domain proximal to the membrane while the second, more distal domain appears to have regulatory functions.

Both putative phosphatase domains of CPTP1 detect multiple high-molecular-weight transcripts, similar in size to receptor PTPases. In addition, they both show high sequence similarity to LAR and HPTP $\delta$, two receptor PTPases. Thus, the sequence, as well as the size, of the RNA transcripts detected by CPTP1 strongly suggests that CPTP1 encodes a transmembrane PTPase. The in situ hybridization results presented here show that both domains of CPTP1 are expressed at very high levels in the developing brain. In particular, the ventricular zone of the cortical analage at E15 and E17, where progenitor cells are giving rise to postmitotic neurons, is perhaps the highest region of CPTP1 expression. Expression is markedly downregulated in the adult, suggesting that these putative PTPases may have a role in the proliferation and early differentiation of neurons.

The sequence of CPTP1 is similar to two recently reported phosphatase domains isolated by PCR from human pre-B-cell cDNA (Adachi et al., 1992). Like CPTP1, these two PCR products (240 bp each) show high similarity to human LAR and HPTP $\delta$. One of the pre-B-cell clones is $93 \%$ identical in peptide sequence and $83 \%$ identical in nucleotide sequence to the first domain of CPTP1. The other clone differs in only two of its 80 amino acids from the second domain ( $96 \%$ peptide, $88 \%$ nucleotide identity). The limited amount of sequence information reported for the pre-B-cell cDNAs prevents us from determining whether CPTP1 represents the rat homolog of this human PTPase.

The putative phosphatase domains of CPTP1 are most similar to LAR and HPTPd, two receptor-like PTPases that are highly similar to one another (63\% in the extracellular region, $88 \%$ in the intracellular region). The extracellular domains of LAR and HPTP $\delta$ contain three Ig-like repeats and eight FN-III-like repeats (Saito and Streuli, 1991). The combination of Ig- and FNIII-like repeats is also found in cell adhesion molecules like NCAM (Rutishauser, 1983), fasciclin II, neuroglian (Grenningloh et al., 1990), and TAG-1 (Furley et al., 1990), as well as in a tumor suppressor gene product, DCC (deleted in colorectal carcinomas) (Fearon et al., 1990). The extracellular domains of NCAM, fasciclin II, and neuroglian mediate homophilic binding (Rutishauser, 1983; Grenningloh et al., 1990). Homophilic binding has not been reported for any of the receptor PTPases, nor have other ligands for the extracellular domains of almost any receptor PTPases (except for CD45) been identified. The high degree of similarity among the phosphatase domains of CPTP1, LAR, and HPTP $\delta$ leads to the prediction that the extracellular region of CPTP1 will also contain Ig- and FN-II-like motifs. Such a structure might allow CPTP1 to play a dual role, cell-cell (or cell-matrix) adhesion and signal transduction, in neuronal differentiation.

\section{CPTPI may give rise to more than a single gene product}

On Northern blots both putative phosphatase domains of CPTP1 recognize multiple transcripts, with two prominent bands at 7.8 and $6.5 \mathrm{~kb}$. The presence of multiple bands may be due to 
differential processing of mRNA from a single gene, to the existence of multiple genes encoding the CPTPs, or to cross-hybridization to other mRNAs. Several lines of evidence support the first of these possibilities, that is, the presence of differential splicing and/or polyadenylation sites. First, on genomic Southern blots, carried out under high-stringency conditions, CPTP1 hybridizes to a single gene. Second, it is not likely that the two bands represent cross-hybridization to other gene products, such as rat LAR, because the calculated melting temperature of CPTP1-LAR hybrids is lower than the stringency conditions used for the Northern blots. In fact, all bands remain present when the stringency of the Northern is increased by raising the wash temperature to $70^{\circ} \mathrm{C}$. Furthermore, Northerns using the rat LAR domain I as a probe detect a single band around $8 \mathrm{~kb}$ and never reveal the $6.5 \mathrm{~kb}$ band. Taken together, these data indicate that the 6.5 and $7.8 \mathrm{~kb}$ CPTP1 transcripts represent two different mRNAs derived from a single gene, distinct from rat LAR.

Many receptor PTPases, including CD45 (Streuli et al., 1987), LAR (Zhang and Longo, 1992), LRP (Matthews et al., 1990; Sap et al., 1990), DPTP10D and DPTP99A ( Tian et al., 1991; Yang et al., 1991), have variants with different splicing and polyadenylation sites. Alternative splicing of the CD45 gene is particularly interesting because it occurs in the region encoding the extracellular domain of the molecule. Eight isoforms of CD45 are produced using all possible combinations of the three exons encoding the extracellular domain (Trowbridge, 1991). These isoforms are expressed by different cell types and may have different ligands (Thomas, 1989). Therefore, receptor PTPases have the potential to generate a large number of cell type-specific isoforms by alternative splicing. This raises the possibility that different isoforms of CPTP1 may be expressed by different groups of neural cells. Until we obtain additional sequence of these transcripts, we will not be able to resolve possible differential distributions of the mRNAs. However, the differential temporal regulation of the two major CPTP1 transcripts is consistent with this hypothesis. The expression of $7.8 \mathrm{~kb}$ and $6.5 \mathrm{~kb}$ transcripts is regulated differently during neural development. On Northern blots, the $7.8 \mathrm{~kb}$ band is expressed at very high levels in the embryonic cortex while the $6.5 \mathrm{~kb}$ is not detected in the cortex until after birth. The in situ signal detected in the CNS of embryos therefore reflects the expression of the $7.8 \mathrm{~kb}$ message, while the signal detected in postnatal brain most likely reflects expression of both 7.8 and $6.5 \mathrm{~kb}$ messages. The differential regulation of the two CPTP1 mRNAs suggests that the two transcripts may encode gene products with different functions during pre- and postnatal brain development. We are currently pursuing this possibility by screening a cDNA library as well as by raising antibodies to analyze protein expression.

\section{CPTP2 may encode a nonreceptor PTPase}

CPTP2 recognizes a $3.5 \mathrm{~kb}$ message with more sequence homology to nonreceptor than to receptor PTPases. Two groups have recently reported PCR-generated clones with very high homology to CPTP2. The deduced amino acid sequence of C.PTP2 is identical to a sequence isolated from mouse myeloid leukemia cells (Yi et al., 1991) and is highly similar (one out of 107 amino acids different) to a sequence from rat kidney cDNA (Moriyama et al., 1992). Although the nucleic acid sequence was not reported, the molecular weight and tissue distribution of the mouse myeloid mRNA are similar to CPTP2. These sequence data strongly suggest that CPTP2, the mouse myeloid
PTPase, and the rat kidney PTPase all represent a single, ubiquitously expressed, nonreceptor PTPase.

One major difference between the mouse myeloid PTPase and CPTP2 is that the level of the myeloid PTPase expression was reported to be equal in all tissues examined, including fetal and adult brain. This is in contrast to the downregulation of CPTP2 we report here. The difference may be explained by the use of $\beta$-actin as a control for equal loading of RNAs probed with the myeloid PTPase probe. In the brain, actin isoforms are expressed at much higher levels during development than in the adult (Schmitt et al., 1977). An actin control may, then, have resulted in an underestimation of the mouse myeloid PTPase mRNA in the fetal brain.

Nontransmembrane PTPases have been isolated from the brain by other groups. T-cell PTPase (Cool et al., 1989), rat PTPase-1 (Guan et al., 1990), and STEP (striatum-enriched phosphatase; Lombroso et al., 1991) are expressed in the brain. Rat PTPase-1 is found at high levels in adult hippocampus, while STEP is primarily expressed in the adult striatum. The developmental expression profiles of these genes have not been reported. At present, CPTP2 is the only putative nonreceptor PTPase that shows preferentially high levels of expression in embryonic brain. Our in situ hybridization results show that the CPTP2 is expressed at highest level in the developing cortex during the embryonic period, the time of rapid cellular proliferation. As development continues, the level of CPTP2 expression in the CNS decreases such that only a low level of expression can be detected in the adult cortex or spinal cord. CPTP2 expression in the adult liver is about the same as in the adult brain, much less than the embryonic brain.

During the prcparation of this report, a full cDNA sequence of a phosphatase from murine P19EC cells (named P19-PTP) appeared in the GenBank. At the nucleic acid level CPTP2 shows 93\% homology to P19-PTP. The deduced peptide sequence of the phosphatase domain of P19-PTP is identical to the CPTP2 peptide sequence except for one amino acid (Den Herzog et al., 1992). The tissue distribution and developmental regulation of P19-PTP has not been reported, but based on size and sequence information, P19-PTP is likely to be the murine homolog of CPTP2.

\section{Potential roles for PTPases in the developing brain}

CPTP1 and CPTP2 both encode putative PTPases that are widely distributed in the developing CNS. Within the cortex, both CPTP2 and the $7.8 \mathrm{~kb}$ transcript of CPTP1 show very high lcvels of expression during the period of corticogenesis. Both are also expressed at high levels in the external granule cell layer of the developing cerebellum and are downregulated throughout the nervous system in adult animals. Such temporal regulation of expression suggests that these PTPases may be involved in proliferation, migration, and early differentiation of neurons. The $6.5 \mathrm{~kb}$ CPTP1 message is expressed at the same level throughout the postnatal period, implying that it has a constitutive role in mature neural functions.

The role of intercellular interactions in normal physiological processes and during development is well established. With the identification of increasing numbers of cell-cell and cell-matrix adhesion molecules, greater insights into the molecular mechanisms underlying cellular interactions have been gained. For example, it has become increasingly clear that cell adhesion is not merely a matter of extracellular stickiness, but is a complex 
phenomenon involving transmembrane signaling and cytoplasmic responses. This has been demonstrated most clearly in the immune system. For instance, in the interaction between leukocytes and endothelium, initial adhesion leads to "activation" of the leukocytes that is mediated by second messengers (Springer, 1990; Butcher, 1991). Similarly, the binding of helper T-cells to antigen-presenting cells is followed by cytoskeletal reorganization and is regulated by phosphorylation (Kupfer and Singer, 1989). Both events involve cell adhesion molecules of the Ig and integrin families. Similar signaling mediated by integrins is involved in adhesive functions of platelets (reviewed in Shattil and Brugge, 1991).

In the developing nervous system, the molecular mechanisms that underlie processes such as neuronal migration and axonal guidance are being studied in detail (Bixby and Harris, 1991; Hynes and Lander, 1992). While many cell adhesion molecules have been shown to play a role in these processes, the signal transduction mechanism by which cell surface events are translated into cellular responses is poorly understood. Many cellular processes are regulated by protein phosphorylation, balanced by the competing activities of kinases and phosphatases. Cellcell contacts and protein phosphorylation can reflect two components of a single process, as illustrated by genetic studies in Drosophila. Null mutations of either the cell adhesion molecule (fasciclin $I$ ) or a cytoplasmic PTK $(a b l)$ have little observable effect on the nervous system. However, embryos double mutant for fasciclin $I$ and $a b l$ show a pronounced disorganization of the nervous system, presumably due to a developmental misrouting of growth cones (Elkins et al., 1990). The identification of two receptor PTPases expressed on subsets of growing axons in Drosophila further suggests that a PTPase might perform both cellcell recognition and intracellular signaling functions during development (Tian et al., 1991; Yang et al., 1991); however, the test of such a hypothesis has not yet been reported.

In vitro studies of vertebrate neurons also suggest that tyrosine phosphorylation regulated by extracellular signals is involved in neurite outgrowth. Inhibition of PTKs by genistein facilitates substrate-induced neurite outgrowth (Bixby and Jhabvala, 1992). Furthermore, binding of soluble L1 and NCAM to growth cone membranes reduces tyrosine phosphorylation of tubulin (Atashi et al., 1992). Although the mechanism of the decreased phosphorylation is not known, PTPases may be involved either by directly dephosphorylating tubulin or by regulating the activity of the PTKs. PTPases such as CD45 and LRP have already been shown to regulate src family PTKs (Sefton and Campbell, 1991; Zheng et al., 1992).

The distribution of the PTPases described here suggests a role in cell-cell communication early in neural development. In the developing cortex and brainstem, CPTP1 and CPTP2 are expressed in many areas, but both are most abundant in the regions immediately surrounding the ventricles, which are the site of cellular proliferation. While the cells that occupy the proliferative zones of the embryonic brain are largely homogeneous in appearance, they give rise to all of the phenotypically diverse types of neurons and glia in the mature brain (for discussion, see Geschwind and Hockfield, 1989). The mechanisms that control cellular differentiation have been the object of intensive study over the last several years. Reports from two laboratories indicate that some aspects of the cell fate are determined as a consequence of signals transmitted and received during the terminal mitosis (Reh and Kljavin, 1989; McConnell and Kaznowski, 1991). The potential dual roles of receptor PTPases as cell adhesion and transmembrane signaling proteins would be well suited to mediate this kind of signal transduction.

Receptor PTPases and membrane associated nonreceptor PTPases, including LAR, LRP, and the CPTPs identified in this study, are new candidates that may play adhesion and/or signaling roles mcdiating the accuratc assembly of the nervous system. It might be safely predicted that the full repertoire of PTPases expressed in the brain has not yet been explored. While the sequences we described here are expressed quite abundantly in the neonatal cortex and throughout the developing nervous system, members of the PTPase family expressed in more specific temporal and spatial patterns probably remain to be discovered.

\section{Note added in proof}

The sequence of CPTP1 reported here corresponds to a portion of two sequences that recently appeared in GenBank (accension nos. L11587 and L12329).

\section{References}

Adachi M, Sekiya M, Arimura Y, Takekawa M, Itoh F, Hinoda Y, Imai K, Yachi A (1992) Protein-tyrosine phosphatase expression in pre-B cell NALM-6. Cancer Res 52:737-740.

Aparicio LF, Ocrant I, Boylan JM, Gruppuso PA (1992) Protein tyrosinc phosphatase activation during nerve growth factor-induced neuronal differentiation of PC12 cells. Cell Growth Differ 3:363-367.

Atashi JR, Klinz SG, Ingraham CA, Matten WT, Schachner M, Maness PF (1992) Neural cell adhesion molecules modulate tyrosine phosphorylation of tubulin in nerve growth cone membranes. Neuron $8: 831-842$.

Baker NE, Rubin GM (1989) Effect on eye development of dominant mutations in Drosophila homologue of EGF receptor. Nature 340: $150-153$.

Bixby JL, Harris WA (1991) Molecular mechanisms of axon growth and guidance. Annu Rev Cell Biol 7:117-159.

Bixby JL, Jhabvala P (1992) Inhibition of tyrosine phosphorylation potentiates substrate-induced neurite growth. J Neurobiol 23:468480.

Bothwell A, Yancopoulos GD, Alt FW (1990) Methods for cloning and analysis of eukaryotic genes. Boston: Jones and Bartlett.

Butcher EC (1991) Leukocyte-endothelial cell recognition: three (or more) steps to specificity and diversity. Cell 67:1033-1036.

Chao MV (1992) Neurotrophin receptors: a window into neuronal differentiation. Neuron 9:583-593.

Charbonneau H, Tonks NK (1992) 1002 protein phosphatases? Annu Rev Cell Biol 8:463-493.

Church GM, Gilbert W (1984) Genomic sequencing. Proc Natl Acad Sci USA 81:1991-1995.

Cool DE, Tonks NK, Charbonneau H, Walsh KA, Fischer EH, Krebs EG (1989) cDNA isolated from a human T-cell library encodes a member of the protein-tyrosine-phosphatase family. Proc Natl Acad Sci USA 86:5257-5261.

Danielson PE, Forss-Petter S, Brow MA, Calavetta L, Douglass J, Milner RJ, Sutcliffe JG (1988) p1B15: a cDNA clone of the rat mRNA encoding cyclophilin. DNA 7:261-267.

Den Herzog J, Pals CEGM, Jonk LJC, Kruijer W (1992) Differential expression of a novel murine non-receptor protein tyrosine phosphatase during differentiation of P19 embryonal carcinoma cells. Biochem Biophys Res Commun 184:1241-1249.

Elkins T, Zinn K, McAllister L, Hoffman FM, Goodman CS (1990) Genetic analysis of a Drosophila neural cell adhesion molecule: interaction of fasciclin $I$ and abelson tyrosine kinase mutations. Cell 60:565-575.

Fearon ER, Cho KR, Nigro JM, Simons JW, Ruppert JM, Hamilton SR, Preisinger AC, Thomas G, Kinzler KW, Vogelstein B (1990) Identification of a chromosome 18q gene that is altered in colorectal cancers. Science 247:49-56.

Fischer EH, Charbonneau H, Tonks NK (1991) Protein tyrosine phosphatases: a diverse family of intracellular and transmembrane enzymes. Science 253:401-406.

Frank DA, Sartorelli AC (1988) Alterations in tyrosine phosphory- 
lation during the granulocytic maturation of HL-60 leukemia cells. Cancer Res 48:52-58.

Furley AJ, Morton SB, Manalo D, Karagogeos D, Dodd J, Jessell TM (1990) The axonal glycoprotein TAG-1 is an immunoglobulin superfamily member with neurite outgrowth-promoting activity. Cell 61:157-170.

Genetics Computer Group (1991) Program manual for the GCG package, version 7. Madison, WI: Genetics Computer Group.

Geschwind DH, Hockfield S (1989) Identification of proteins that are developmentally regulated during early cerebral corticogenesis in the rat. J Neurosci 9:4303-4317.

Grenningloh G, Bieber AJ, Rehm EJ, Snow PM, Traquina ZR, Hortsch M, Patel NH, Goodman CS (1990) Molecular genetics of neuronal recognition in Drosophila: evolution and function of immunoglobulin superfamily cell adhesion molecules. Cold Spring Harbor Symp Quant Biol 55:327-340.

Guan K, Haun RS, Watson SJ, Geahlen RL, Dixon JE (1990) Cloning and expression of a protein-tyrosine-phosphatase. Proc Natl Acad Sci USA 87:1501-1505.

Hockfield S, McKay RDG (1985) Identification of major cell classes in the developing mammalian nervous system. J Neurosci 5:3310 3328.

Hockfield S, Sur M (1990) Monoclonal antibody Cat-301 identifies $\mathrm{Y}$-cells in the dorsal lateral geniculate nucleus of the cat. J Comp Neurol 300:320-330.

Hynes RO, Lander AD (1992) Contact and adhesive specificities in the associations, migrations and targeting of cells and axons. Cell 68 : 303-322.

Klambt C, Glazer L, Shilo B-Z (1992) breathless, a Drosophila FGF receptor homolog, is essential for migration of tracheal and specific midline glial cells. Genes Dev 6:1668-1678.

Krueger NX, Streuli M, Saito H (1990) Structural diversity and evolution of human receptor-like protein tyrosine phosphatases. EMBO J 9:3241-3252.

Kupfer A, Singer SJ (1989) The specific interaction of helper T cells and antigen-presenting $B$ cells. IV. Membrane and cytoskeletal reorganizations in the bound $\mathrm{T}$ cell as a function of antigen dose. J Exp Med 170:1697-1713.

Lai C, Lemke G (1991) An extended family of protein-tyrosine kinase genes differentially expressed in the vertebrate nervous system. Neuron 6:691-704

Lathe R (1985) Synthetic oligonucleotide probes deduced from amino acid sequence data: theoretical and practical considerations. J Mol Biol 183:1-12.

Lenoir D, Battenberg E, Bloom FE, Milner RJ (1986) The brainspecific gene $1 \mathrm{~B} 236$ is expressed postnatally in the developing brain. J Neurosci 6:522-530.

Lombroso PJ, Murdoch G, Lerner M (1991) Molecular characterization of a protein-tyrosine-phosphatase enriched in striatum. Proc Natl Acad Sci USA 88:7242-7246.

Maher PA (1991) Tissue-dependent regulation of protein tyrosine kinase activity during embryonic development. J Cell Biol 112:955963.

Martin KA, Grant SGN, Hockfield S (1992) The mas proto-oncogene is developmentally regulated in the rat central nervous system. Dev Brain Res 68:75-82.

Matthews RJ, Cahir ED, Thomas ML (1990) Identification of an additional member of the protein-tyrosine-phosphatase family: evidence for alternative splicing in the tyrosine phosphatase domain. Proc Natl Acad Sci USA 87:4444-4448.

Matthews RJ, Browne DB, Flores E, Thomas ML (1992) Characterization of hematopoietic intracellular protein tyrosine phosphatases: description of a phosphatase containing an $\mathrm{SH} 2$ domain and another enriched in proline-, glutamic acid-, serine-, and threonine-rich sequences. Mol Cell Biol 12:2396-2405.

McConnell SK, Kaznowski CE (1991) Cell cycle dependence of laminar determination in developing neocortex. Science 254:282-285.

Moriyama T, Fujiwara Y, Imai E, Takenaka M, Kawanishi S, Inoue T, Noguchi T, Tanaka T, Kamada T, Ueda N (1992) cDNA cloning of rat LRP, a receptor like protein tyrosine phosphatase, and evidence for its gene regulation in cultured rat mesangial cells. Biochem Biophys Res Commun 188:34-39.
Pot DA, Dixon JE (1992) A thousand and two protein tyrosine phosphatases. Biochim Biophys $\Lambda$ cta 1136:35-43.

Pot DA, Woodford TA, Remboutsika E, Haun RS, Dixon JE (1991) Cloning, bacterial expression, purification, and characterization of the cytoplasmic domain of rat LAR, a receptor-like protein tyrosine phosphatase. J Biol Chem 266:19688-19696.

Reh TA, Kljavin IJ (1989) Age of differentiation determines rat retinal germinal cell phenotype: induction of differentiation by dissociation. J Neurosci 9:4179-4189.

Rubenstein JLR, Brice AEJ, Ciaranello RD, Denney D, Porteus MH, Usdin TB (1991) Subtractive hybridization system using singlestranded phagemids with directional inserts. Nucleic Acids Res 18: $4833-4842$.

Rubin GM (1991) Signal transduction and fate of the R7 photoreceptor in Drosophila. Trends Genet 7:372-377.

Rutishauser U (1983) Molecular and biological properties of a neural cell adhesion molecule. Cold Spring Harbor Symp Quant Biol 48: $501-526$

Saito H, Streuli M (1991) Molecular characterization of protein tyrosine phosphatases. Cell Growth Differ 2:59-65.

Sambrook J, Fritsch EF, Maniatis T (1989) Molecular cloning: a laboratory manual, $2 \mathrm{~d}$ ed. Cold Spring Harbor, NY: Cold Spring Harbor Laboratory.

Sap J, D'Eustachio P, Givol D, Schlessinger J (1990) Cloning and expression of a widely expressed receptor tyrosine phosphatase. Proc Natl Acad Sci USA 87:6112-6116.

Schejter ED, Shilo B-Z (1989) The Drosophila EGF receptor homolog (DER) gene is allelic to faint little ball, a locus essential for embryonic development. Cell 56:1093-1104.

Schlessinger J, Ullrich A (1992) Growth factor signaling by receptor tyrosine kinases. Neuron 9:383-391.

Schmitt H, Gozes I, Littauer UZ (1977) Decrease in levels and rates of synthesis of tubulin and actin in developing rat brain. Brain Res 121:327-342.

Sefton BM, Campbell M-A (1991) The role of tyrosine protein phosphorylation in lymphocyte activation. Annu Rev Cell Biol 7:257274.

Shattil SJ, Brugge JS(1991) Protein tyrosine phosphorylation and the adhesive functions of platelets. Curr Opin Cell Biol 3:869-879.

Shilo B-Z (1992) Roles of receptor tyrosine kinases in Drosophila development. FASEB J 6:2915-2922

Springer TA (1990) Adhesion receptors of the immune system. Science 346:425-433

Streuli M, Hall LR, Saga Y, Schlossman SF, Saito H (1987) Differential usage of three exons generates at least five different mRNAs encoding human leukocyte common antigens. J Exp Med 166:1548-1566.

Streuli M, Krueger NX, Hall LR, Schlossman SF, Saito H (1988) A new member of the immunoglobulin superfamily that has a cytoplasmic region homologous to the leukocyte common antigen. J Exp Med 168:1553-1562.

Thomas ML (1989) The leukocyte common antigen family. Annu Rev Immunol 7:339-369.

Tian S-S, Tsoulfas P, Zinn K (1991) Three receptor-like protein-tyrosine phosphatases are selectively expressed on central nervous system axons in the Drosophila embryo. Cell 67:675-685.

Trowbridge IS (1991) CD45: a prototype for transmembrane protein tyrosine phosphatases. J Biol Chem 266:23517-23520.

Wagner KR, Me L, Huganir RL (1991) Protein tyrosine kinases and phosphatases in the nervous system. Curr Opin Neurobiol 1:65-73.

Yang X, Seow KT, Bahri SM, Oon SH, Chia W (1991) Two Drosophila receptor-like tyrosine phosphatase genes are expressed in a subset of developing axons and pioneer neurons in the embryonic CNS. Cell 67:661-673.

Yi T, Cleveland JL, Ihle JN (1991) Identification of novel protein tyrosine phosphatases of hematopoietic cells by polymerase chain reaction amplification. Blood 78:2222-2228.

Zhang JS, Longo FM (1992) LAR tyrosine phosphatase receptor: a novel GC-rich transcript expressed in rat CNS. Soc Neurosci Abstr $18: 949$

Zheng XM, Wang Y, Pallen CJ (1992) Cell transformation and activation of pp60 (c-src) by overexpression of a protein tyrosine phosphatase. Nature 359:336-339. 